\title{
A SENSIBILIZAÇÁO CORPORAL NAS AULAS DE DANÇA CLÁSSICA
}

\author{
BODY AWARENESS IN CLASSIC DANCE CLASSES
}

\section{LA SENSIBILIZACIÓN CORPORAL EN LAS CLASES DE DANZA CLÁSICA}

Rosana Lobo ROSÁRIO

\section{Resumo}

Este artigo é parte integrante da tese de doutoramento em Artes, em andamento, na Universidade de Lisboa - Portugal, e tem como objetivo refletir sobre o processo de sensibilizaçáo corporal nas aulas de dança clássica desenvolvidas durante a investigação doutoral. Para a coleta de dados, fez-se uso da metodologia da investigação-ação com os estudantes do Curso Técnico de Dança Clássica da Escola de Teatro e Dança da Universidade Federal do Pará - ETDUFPA. Esses dados foram analisados à luz dos estudos da educação somática (Hanna, 1986; Fortin, 1999; Bolsanello, 2010), do conceito de sensibilização (Imbassaí, 2003) e da fenomenologia da percepção (Merleau-Ponty, 2015). Os resultados mostraram que o processo de sensibilizaçáo corporal nas aulas de dança clássica contribuiu para a percepçáo corporal dos participantes e para modificaçôes dos padróes de movimento, o que traz à tona discussóes a respeito da construção do conhecimento em dança clássica e de novas formas de fazer e pensar este ensino pautado no indivíduo. Conclui-se que o processo de sensibilização nas aulas de dança clássica prioriza o conhecimento voltado para a formação do bailarino como ser uno, integral, além de produzir subsídios epistemológicos sobre o processo de ensino e aprendizagem do movimento corporal.

\footnotetext{
${ }^{1}$ Professora da Escola de Teatro e Dança da Universidade Federal do Pará (Brasil) e Bolsista CAPES do curso de doutoramento em Artes, da Universidade de Lisboa (Portugal), sob a orientação da professora doutora Maria José Fazenda (ESD) e coorientaçáo da professa doutora Vanda Nascimento (ESD) e professor doutor Jorge Ramos (IE). E-mail: rosanaloborosario@hotmail.com 
Palavras-chave: educação somática; sensibilização; dança clássica; ensino; aprendizagem.

\section{Resumen}

Este artículo es parte de la tesis doctoral en Artes, en progreso, en la Universidad de Lisboa-Portugal y tiene como objetivo reflexionar sobre el proceso de sensibilización del cuerpo en las clases de danza clásica desarrolladas durante la investigación doctoral. Para la recolección de datos, se hizo uso de la metodología de investigación acción con los alumnos del Curso Técnico de Danza Clásica en la Escuela de Teatro y Danza en la Universidad Federal de Pará - ETDUFPA. Estos datos fueron analizados a la luz de los estudios de la educación somática (Hanna, 1986; Fortin, 1999; Bolsanello, 2010), el concepto de sensibilización (Imbassai, 2003) y la fenomenología de la percepción (Merleau-Ponty, 2015). Los resultados mostraron que el proceso de conocimiento del cuerpo en las clases de danza clásica contribuyó a la percepción corporal de los participantes y para modificaciones en los patrones de movimiento, que trae las discusiones sobre la construcción del conocimiento en danza clásica y nuevas formas de hacer y de pensar esta enseñanza con bases en el individuo. Se concluye que el proceso de sensibilización en clases de danza clásica prioriza el conocimiento orientado a la formación del bailarín como ser, integral, además de producir subsidios epistemológicos sobre el proceso de enseñanza y aprendizaje del movimiento corporal.

Palavras clave: educación somática. Sensibilización. danza clásica. Enseñanza. aprendizaje.

\section{Abstract}

his article is part of the doctoral thesis in arts, in progress, at the University of Lisbon-Portugal, and aims to reflect on the process of body awareness in classical dance classes developed during doctoral research. For the data collection, was using the action-research methodology with the students of the Technical Course of Classical Dance at the School of Theatre and Dance at the Federal University of Para-ETDUFPA. These data were analyzed in the light of the studies of somatic education (Hanna, 1986; Fortin, 1999; Bolsanello, 2010), the concept of awareness (Imbassai, 2003) and the phenomenology of perception (Merleau-Ponty, 2015). The results showed that the 
body sensitization process in classical dance classes contributed to the body perception of the participants and to changes in movement patterns, which brings up discussions about the construction of knowledge in classical dance and new ways of doing and think this teaching based on the individual. It is concluded that the awareness-raising process in classical dance lessons prioritizes the knowledge focus on the formation of the dancer as a whole, integral, besides producing epistemological subsidies on the teaching and learning process of the body movement.

KEYWORDS: somatic education. Awareness. classical dance. Teaching. Learning.

\section{INTRODUÇÃO}

Nos estudos realizados acerca da história e do ensino da dança clássica (Homans, 2012; Vianna, 2005), verificouse que ocorreram diversas mudanças no processo de ensino e aprendizagem desta técnica em sala de aula, e também nas concepçóes coreográficas apresentadas em palcos. Nessa perspectiva, observou-se que a técnica da dança clássica deve ser compreendida como um caminho e um processo de investigação em constantes mudanças (VIANNA, 2005). Além disso, é possível considerá-la um procedimento que se transforma, sem que haja perdas dos seus fundamentos básicos, codificados no século XVI e que ainda hoje permanecem os mesmos, apesar do tempo e dos locais em que foram sistematizadas as escolas de dança clássica, tais como a francesa, a inglesa, a russa, a italiana e a cubana.

Contudo, apesar de todas essas transformaçōes, observa-se que a maioria das aulas de técnicas de dança ainda é conduzida de modo tradicional, ou seja, o professor apresenta as sequências de movimentos, que são organizadas em uma determinada ordem, e os alunos devem se apropriar e reproduzi-las. Além disso, o corpo do bailarino continua sendo olhado de fora, ou seja, do ponto de vista de uma terceira pessoa, geralmente do professor, que, por sua vez, 
não somente serve de modelo, mas também é quem oferece parâmetros do que é certo e errado, e quais os resultados são esperados (Souza, 2012).

No entanto, num estudo desenvolvido por Rosário (2016), foi verificado que as experiências pedagógicas em dança clássica, quando realizadas sob o viés da educação somática, possibilitam novos caminhos de investigação e criação, alterando os modos de fazer dança. Nesse sentido, este artigo tem como objetivo refletir sobre a educação somática, em especial o método Gyrokinesis, principalmente no que se refere ao processo de sensibilização corporal nas aulas de dança clássica. Para tal, a partir da pesquisa de campo realizada no âmbito dos estudos doutorais em artes, da Universidade de Lisboa, em Portugal, utilizou-se a metodologia da investigaçãoação, durante o período de três meses, com os estudantes do Curso Técnico de Dança Clássica da Escola de Teatro e Dança da Universidade Federal do Pará - ETDUFPA, no Brasil.

No processo de sensibilizaçáo, esses estudantes vivenciaram o método Gyrokinesis, criado e sistematizado por Horvath nos anos 1970, e posteriormente realizaram aulas de dança clássica com base nas vivências somáticas proporcionadas pelo referido método. Nesses encontros, o processo de sensibilização se deu a partir do uso de algumas estratégias da educação somática, as quais compreenderam: o toque, a observação, as comparaçóes sensoriais, o uso de imagens mentais e a repetiçáo do movimento. Paralelo a isto, foi realizado o estudo bibliográfico sobre os conceitos de sensibilização (Imbassaí, 2003) e percepção (MERLEAUPONTY, 2015), a fim de melhor compreender as estratégias utilizadas, bem como dialogar com o material coletado na pesquisa de campo, constituído pelos depoimentos e diários de campo dos participantes.

Após essas considerações e para melhor discussão, este artigo se divide em três seçôes. A primeira, denominada Educação Somática e o Processo de Sensibilização, apresenta a revisão da literatura sobre a educação somática e a relação deste campo de 
conhecimento com os conceitos de percepção e sensibilização. Em seguida, na seção intitulada As Estratégias Somáticas nas Aulas de Dança Clássica, disserta-se sobre a pesquisa de campo realizada, e reflete-se sobre o uso das estratégias somáticas nos encontros com o método Gyrokinesis e nas aulas de dança clássica e seus contributos para o processo de sensibilização corporal. E por fim, na terceira parte, Consideraçóes Finais, são apresentadas as principais questôes discutidas e construídas ao longo do desenvolvimento deste artigo, e que resultaram em uma proposta de ensino de dança clássica a partir do processo de sensibilização, fundamentada na transformação do pensar a dança dos participantes. Além disso, também são apresentadas as lacunas ainda não preenchidas por este artigo, bem como as possibilidades de novos estudos.

\section{A Educação Somática e o Processo de Sensibilização}

A expressão educação somática foi definida pela primeira vez por Hanna (1986) como "the field which studies the soma: namely, the body as perceived from within by first-person perception (...)" (p. 04). Complementando essa definição, Fortin (1999) salienta que a educação somática é um processo relacional interno entre a consciência, o biológico e o meio ambiente, em que estes três fatores são vistos como um todo agindo em sinergia. Neste sentido, Bolsanello (2010) observa que a educação somática é um campo teórico-prático composto por diferentes métodos e técnicas, cujo eixo de atuação é o movimento do corpo como via de prevenção ou de transformação.

Porém, antes da consolidação do termo, aproximadamente entre o final do século XIX e o início do século $\mathrm{XX}$, esses métodos eram vistos como “(...) um movimento heterogêneo em sua constituição, preocupado em repensar o corpo objetualizado, resultante da mecanização operada pela Revolução Industrial e pelo desenvolvimento do capitalismo" (SILVA, 2015, p. 36). 
Eddy (2009), com o objetivo de realizar algumas consideraçôes sobre o surgimento das primeiras propostas somáticas, afirmou que as pesquisas neste campo de conhecimento foram impulsionadas por determinados movimentos, e cita como o principal a Fenomenologia e, com isso, "(...) a gradual shift towards theoretical support for experiential learning and sensory research occurred in parts of the academic and scholarly culture" (p. 06). Nesse sentido, destacamse as contribuiçóes de Merleau-Ponty, principalmente a partir da obra Fenomenologia da Percepção (2015), em que o autor constrói o argumento sobre a importância dos sentidos e da percepção para uma experiência corporal em que o movimento e o sentir são elementos importantes para a percepção e o conhecimento a respeito do mundo. Neste aspecto, o autor afirma:

(...) a percepção sinestésica é regra, e se não percebermos isso, é porque o saber científico desloca a experiência e porque desaprendemos a ver, a ouvir e, em geral, a sentir, para deduzir de nossa organização corporal e do mundo tal como o concebe o físico aquilo que devemos ver, ouvir e sentir (...). (MERLEAU-PONTY, 2015, p. 308).

Esta compreensão da percepção em Merleau-Ponty impulsionou diversas práticas corporais, como também estimulou a busca de novas maneiras de se movimentar para além do deslocamento mecânico das partes do corpo no espaço, dos conteúdos e dos métodos de ensino tradicionais de dança, dentre outros aspectos que configuram as práticas educativas do corpo (EDDY, 2009).

Dessa forma, as práticas corporais desenvolvidas sob este viés possibilitaram a aprendizagem do corpo em movimento a partir das sensaçóes percebidas, as quais devem estar associadas ao ambiente no qual este corpo está inserido. Nesta perspectiva, enquadram-se, como práticas corporais, os métodos e técnicas da educação somática, que por sua vez, “(...) engloba uma diversidade de conhecimentos, nos quais os domínios sensorial, cognitivo, motor, afetivo e espiritual 
se misturam com ênfases diferentes" (FORTIN, 1999, p. 40). Assim, a educação somática nos é apresentada como "um campo teórico e prático que se interessa pela consciência do corpo e seu movimento" (BOLSANELLO, 2005, p. 100).

Strazzacappa (2012) aponta que a história e a criação desses métodos e técnicas estão diretamente relacionadas à história pessoal de quem as criou, tais como a perda de voz de Mathias Alexander, que o fez criar a Técnica de Alexander; a lesão no joelho de Moshe Feldenkrais, que permitiu a sistematização do método Feldenkrais; a doença renal de Mabel Todd, que levou à formação do método Ideokinesis; e o traumatismo do calcâneo de Horvath, que o fez desenvolver os métodos Gyrotonic e Gyrokinesis, entre outros (BOLSANELLO, 2010).

Todos esses métodos colocaram em questionamento a medicina da época praticada nos países da América do Norte e da Europa, porém, é válido ressaltar que os criadores dos métodos somáticos não tinham como objetivo desenvolver técnicas terapêuticas, mas encontrar soluçôes para os seus respectivos problemas, uma vez que não concordavam com as soluçóes oferecidas pela medicina da época (SOUZA, 2012). Neste percurso, os criadores desenvolveram seus próprios métodos a partir da negação do dualismo corpomente (BOLSANELLO, 2010), prevalecendo a crença de que através do sentir, do fazer e do perceber, constrói-se o mundo (SOUZA, 2012).

Assim, nas aulas de educação somática o aluno é estimulado a investigar o movimento, a buscar novos caminhos de movimentação e a perceber o corpo de forma integrada e próxima das suas emoçóes (BOLSANELLO, 2005). Tal fato dialoga com Merleau-Ponty (2015), uma vez que este autor, ao se referir ao corpo e à sua sensibilidade, apresenta a noçáo do corpo como sensível, em sua capacidade de sentir e atribuir sentidos aos acontecimentos. Portanto, a proposta das aulas dos métodos da educação somática é atuar sobre o corpo de modo a sensibilizá-lo, com base no processo de sensibilização

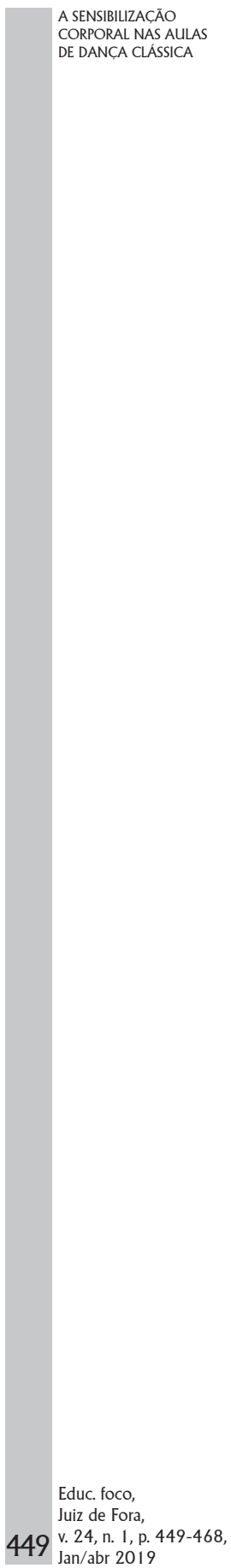


compreendido como "(...) um canal por onde se abrem as portas da percepção do corpo (...)” (IMBASSAÍ, 2003, p. 51).

Neste sentido, sensibilizar e perceber o corpo são duas açóes relacionadas com o processo de conscientização corporal, o qual consiste em um trabalho de autorregulação do tônus muscular e de organização postural a partir do uso de técnicas de relaxamento, micromovimentos e da consciência muscular, ósseo e articular (IMBASSAÍ, 2003). Para melhor compreensão desse processo de percepção e de conscientização, os educadores somáticos utilizam algumas estratégias que “(...) demandam o uso focado da atençáo e da concentração e envolvem habilidades como observar, sentir, perceber, nomear, diferenciar, comparar, interpretar, modular e outras, que contribuem para trazer para o nível da consciência açóes que poderiam facilmente passar despercebidas (...)" (SOUZA, 2012, p. 32).

Essas estratégias contribuem para que o indivíduo realize uma descoberta pessoal, a partir do conhecimento de como o corpo se move e como pode se mover (ROSÁRIO, 2013; SOUZA, 2012). O praticante se transforma, então, num investigador do seu próprio movimento e por meio desse processo investigativo conquista uma posição de autonomia (DOMENICI, 2010). Souza (2012) ainda salienta que neste processo de ensino e aprendizagem das técnicas e métodos somáticos, “(...) o professor assume o papel de facilitador, provocador, propositor de experiências, alguém que aponta possibilidades e sugere caminhos sem, no entanto, determinar os resultados esperados ou o tempo para se chegar até eles" (p. 34).

Nessa perspectiva, a educação somática é compreendida enquanto uma proposta relacionada a como aprender e construir conhecimento, direcionando o praticante em um caminho investigativo do próprio corpo e do próprio movimento. Observa-se, à medida que o indivíduo se apropria dessa dinâmica, que ele se percebe melhor e se torna autônomo, sem depender estritamente da figura do professor dentro da sala de aula. Nesse aspecto, este estudo buscou compreender 
de que maneira esta dinâmica investigativa do e no próprio corpo pode ser articulada num ensino de dança, em especial da dança clássica.

\section{As Estratégias Somáticas nas Aulas de Dança Clássica}

No intuito de responder à questáo levantada anteriormente, foi realizada, no âmbito dos estudos doutorais em Artes da Universidade de Lisboa, Portugal, a pesquisa de campo na Escola de Teatro e Dança da Universidade Federal do Pará - ETDUFPA, no Brasil, com objetivo de investigar os possíveis entrelaçamentos da educação somática na execução das sequências dos movimentos de barra da dança clássica e averiguar os contributos desta experiência para o processo de ensino e aprendizagem em dança clássica com estudantes ingressantes nos anos de 2014 e 2015 no referido curso. Para tal, fez-se uso da metodologia investigação-ação, e a recolha de dados foi feita por meio do uso do vídeo, para o registro dos encontros e dos depoimentos dos participantes; da observaçáo participante dos movimentos realizados; e do diário de campo, para o registro e leitura das percepçóes de cada participante.

Importante ressaltar que, a fim de manter o anonimato dos envolvidos na pesquisa, os nomes verdadeiros foram substituídos por personagens de ballets de repertório2, atribuídos de forma aleatória durante o processo de análise de dados.

Ainda sobre as aulas, os participantes vivenciaram o método Gyrokinesis e fizeram uso de algumas estratégias somáticas, tais como toque de si e do outro, observação de si e do outro, comparaçôes de sensaçóes e partes do corpo, uso de imagens mentais e a repetição do movimento. Em seguida, realizaram aulas de dança clássica a partir do processo de sensibilização enfatizado nas aulas do método Gyrokinesis.

${ }^{2}$ Ballets de repertório, ou Repertório Clássico - do francês ballet d'action - é a forma de ballet originado no século XVII com estrutura teatral, com objetivo de transmitir um enredo, e desta forma possui um roteiro, uma música, uma coreografia, um figurino e um cenário específico (FARO; SAMPAIO, 1989).

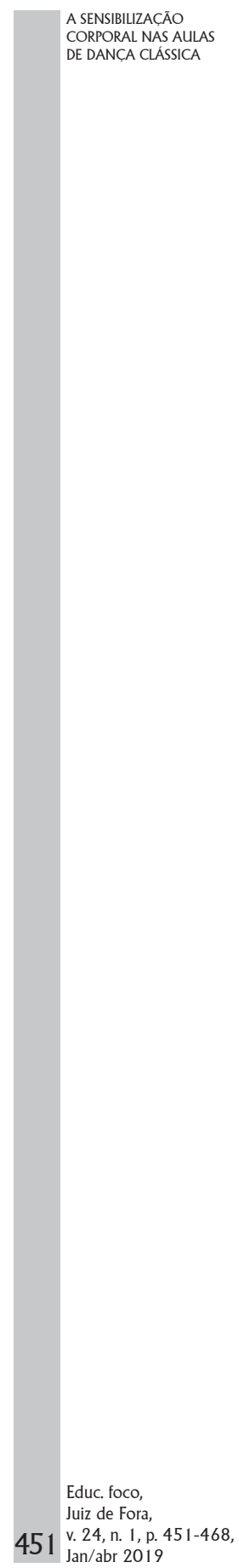


Com o intuito de facilitar a compreensão deste processo de sensibilizaçáo corporal nas aulas de dança clássica, serão descritas nesta seção como cada estratégia da educação somática foi vivenciada, e quais os reflexos dessas estratégias na execução dos movimentos sugeridos. Para isso, fez-se uso dos depoimentos e da leitura dos diários de campo dos participantes em diálogo, principalmente com Imbassaí (2003) sobre o conceito de sensibilização, e Merleau-Ponty (2015), sobre a noção de percepção.

Assim, inicio esta explicação pela estratégia do toque, bastante utilizada no processo de ensino e aprendizagem tanto nos métodos da educação somática, como também na dança (BOLSANELLO, 2005; FRANKLIN, 2012), uma vez que contribui para que o bailarino tenha esclarecimento sobre a execução do movimento (Rosário, 2013). Assim, foram realizadas atividades em duplas para que os participantes compreendessem a movimentação de mobilização da coluna no método Gyrokinesis. O trabalho em dupla consistiu em um participante auxiliar o movimento do outro através do toque e manipulação da coluna vertebral, como verificado na Figura 01.

Figura 1: Trabalho em dupla - Mobilização da Coluna.

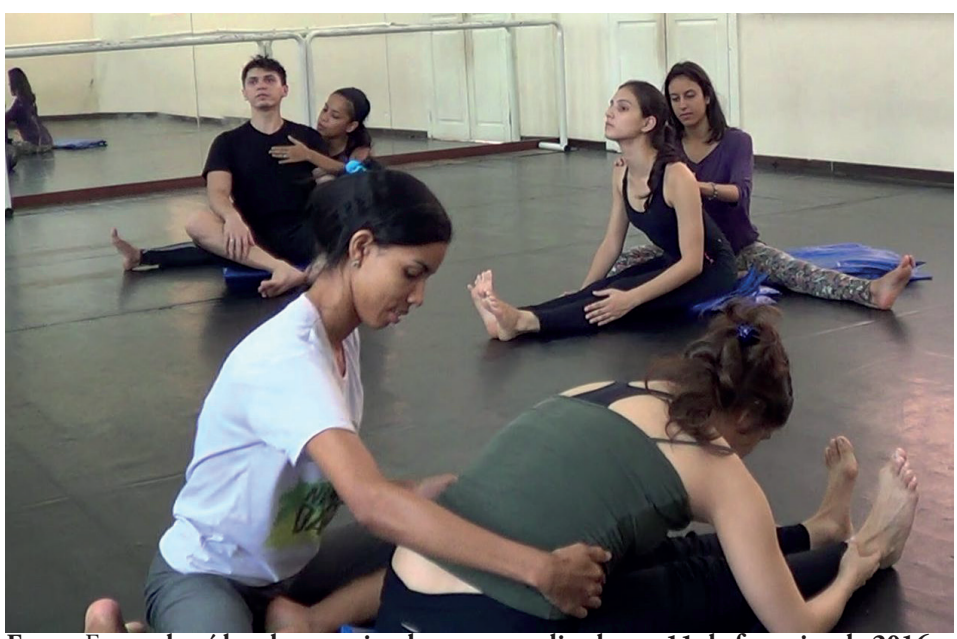

Fonte: Frame do vídeo da pesquisa de campo realizado em 11 de fevereiro de 2016. 
Com o objetivo de facilitar a compreensão sobre a mobilização da coluna, a Figura 1 mostra o toque facilitador para a percepção dos movimentos de arch \& curl do método Gyrokinesis, que trabalham a extensão e flexão da coluna. A figura também mostra alguns participantes direcionando o movimento a partir do tocar, enquanto outros participantes permitem ser tocados, buscando aprender sobre a movimentação da coluna. Essa atividade contribui para a compreensão de como realizar um determinado movimento, seja pelo toque recebido ou fornecido, tal como observado pela participante La Sylphide:

Mas pra mim o toque se torna essencial porque quando você faz isso aqui no meu pé, pegou e puxou, eu senti a intensidade do movimento que tem que ser feito quando eu estiver só. Entáo, o toque do colega já fica no meu corpo. Já tenho a intenção que não tinha quando estava sozinha. Parece que eu sinto a máo do colega, mesmo fazendo o exercício sozinha. Então, hoje, foi super diferente. Não tem comparaçấo do que eu estava fazendo antes (depoimento concedido em 12 de janeiro de 2016).

Além dessas observaçóes, foi verificado que o toque no outro colaborou para que alguns participantes compreendessem movimentos frequentemente utilizados numa aula de dança clássica, por exemplo, o flex, que corresponde à dorsoflexão (Ver Figura 02).

Figura 02: Dorsoflexão.

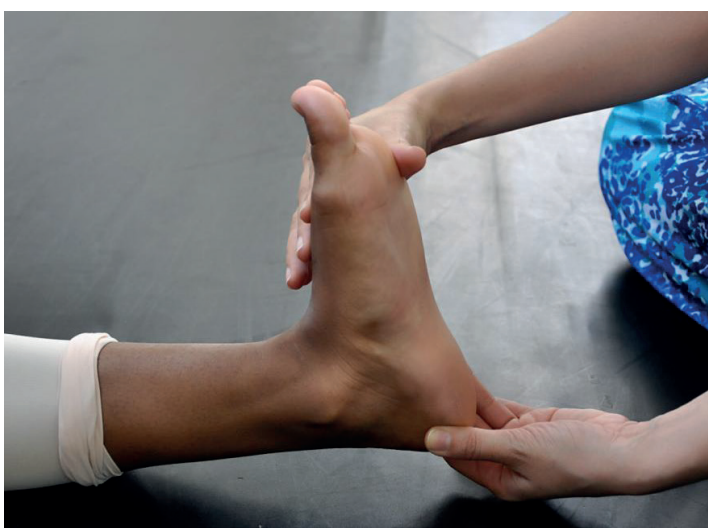


Fonte: Rosário (2013, p. 71).

Tal fato pode ser confirmado no depoimento da participante La Bayadère, ao afirmar:

No começo da aula que a gente estava na parede, que tinha que colocar a mão no calcanhar e empurrar, eu percebi o que era realmente o flex, porque eu fiz e percebi que estava diferente do que eu fazia antes. Eu não sei como eu fazia antes, mas eu não fazia do jeito que comecei a fazer, assim, empurrando o calcanhar. E o toque do colega ajudou bastante. E como isso foi no começo da aula, eu fiz toda a aula pensando no calcanhar (La Bayadère, depoimento concedido em 11 de fevereiro 2016).

Este depoimento, além de evidenciar a importância do toque para a correção do movimento e da consciência corporal, revela ainda que a informação fornecida pelo toque permanece no corpo de quem o recebeu durante toda a aula, até mesmo depois, quando não há mais o toque, apenas movimento.

Além do toque no corpo do outro, também foram desenvolvidas atividades em que cada participante realizou o toque no próprio corpo, o que contribuiu tanto para a compreensão do movimento como também para o conhecimento do próprio corpo.

Teve lugares que eu nunca massageei. Aqui, a têmpora, aqui atrás (occipital). Até a questão de colocar as mãos por dentro da costela. Massagear aqui, eu nunca pensei. E foi uma sensaçáo boa. Parece que me conectei mais com o meu próprio corpo. Então, é como se a gente estivesse conhecendo mais, mesmo. Foi bem relaxante (Corsário, depoimento concedido em 07 de janeiro de 2016).

No depoimento acima, o participante refere-se à atividade de automassagem, realizada com o intuito de estimular o corpo de forma sistêmica. Também foi verificado, a partir dos depoimentos concedidos, bem como no registro do diário de campo, que após a automassagem, os participantes 
relataram maior facilidade no reconhecimento de detalhes do próprio corpo até entáo desconhecidos, ou até mesmo não observados por eles. Nesse sentido, o processo de sensibilizaçáo desenvolvido na pesquisa de campo foi, em grande parte, uma experiência tátil, que, a partir das atividades realizadas, proporcionou aos participantes o conhecimento do próprio corpo, bem como a compreensão dos movimentos sugeridos.

Além disso, o uso dessa estratégia trouxe resultados mais imediatos para a percepção e correçáo de movimentação do que somente as palavras o fariam, insuficientes para a compreensão. Dessa forma, observa-se que a qualidade do toque é um importante instrumento no processo de ensino e aprendizagem em dança, pois auxilia o praticante a perceber, sentir, corrigir e compreender o movimento do/no corpo, a partir do conhecimento anatômico e cinestésico, contribuindo assim para a percepção corporal.

Imbricada à estratégia do toque, encontra-se a da observaçáo, a qual demonstrou ser uma importante ferramenta de ensino e aprendizagem na pesquisa de campo, pois permitiu que os participantes percebessem o próprio corpo, bem como possibilitou que encontrassem novas maneiras de se movimentar.

Com relação a este aspecto, considero válido destacar o depoimento de uma das participantes sobre o ato de observar a si e ao outro, através do qual foi possível perceber o próprio corpo e o movimento que estava sendo realizado, para em seguida encontrar novas formas de se movimentar, evitando tensôes e dores musculares.

(...) quando chegou na metade dos movimentos da coluna eu senti a minha lombar. Aí eu vi que eu não estava alongando. Não estava trabalhando. Aí comecei a prestar atenção no que a senhora estava fazendo. Aí eu vi que, assim, o segredo era mexer os ísquios no banco pra poder mexer a lombar e não só essa parte da torácica. Eu comecei a fazer e comecei 
a sentir também que estava alongando (La Bayadère, depoimento concedido em 14 de janeiro de 2016).

Conforme o depoimento, as observaçóes de si e do outro permitiram à participante realizar alteraçóes corporais, transformando a forma de se movimentar. Tal fato complementa os dizeres de Vianna (2005), quando afirma que a observação é algo obrigatório, pois é ela que faz o indivíduo estar mais vivo, ouvir mais, olhar com mais atenção, refletir e obter informaçóes diferentes sobre o próprio corpo.

Durante a pesquisa de campo, a observação de si possibilitou também o conhecimento anatômico do próprio corpo, tal como afirma a participante Cinderella, ao relatar: “(...) conhecer esses ossos [quadril] é bem estranho, porque eu não tenho o hábito de ficar observando o meu corpo (...) a gente acaba visando só a técnica e não conhece o corpo, por isso que a gente se machuca" (CINDERELLA, 2016, 07 de janeiro). Esta reflexão ratifica o que Lawson (1984) e Strazzacappa (2012) abordam sobre a importância do estudo anatômico nas aulas de dança, uma vez que o ato de se conhecer, anatomicamente, contribui para a prevenção de lesóes durante a prática.

Dessa forma, a observação de si corroborou para o conhecimento do próprio corpo, bem como informou sobre as possibilidades desse corpo, pois a partir da ação de observar, os participantes encontraram novas formas de se movimentar, evitando, inclusive, os desgastes de estruturas anatômicas, muitas vezes sobrecarregadas pelo uso repetitivo e inconsciente.

A terceira estratégia utilizada foi a comparação de partes do corpo e de sensaçóes, que imbricada à estratégia do toque e da observação, ocorreu, principalmente, em dois momentos: 1- na realização de uma atividade em um dos lados do corpo em que, antes de realizar o outro lado, os participantes eram estimulados a comparar e identificar diferenças existentes de cada lado; e 2 - comparaçôes das sensaçôes e das diferenças corporais antes e depois de uma atividade realizada, sem 
estabelecer claramente a seção destinada às atividades sensoriais e as atividades motoras.

O primeiro momento ocorreu nas sessóes de automassagem, em que, ao realizar em um pé o trabalho lento nas articulaçôes, no colo e no arco do pé, afastando e alongando os dedos, os participantes foram incentivados a observar se havia alguma diferença entre o pé que havia recebido a automassagem e o outro. Os participantes identificaram algumas diferenças, referindo-se às sensaçôes de "leveza", "pés espalhados", de que "todos os ossos tocam no chão", e com isso, acarretaram maior mobilidade nos pés.

A estratégia das comparaçóes permitiu também que os participantes percebessem estados emocionais, dores e/ ou regióes de tensão, e reconhecessem o funcionamento do próprio corpo. A partir dessas percepçóes, foram capazes de autorregular seus corpos, uma vez que toda aula de conscientização corporal tem como proposta "atuar sobre o aparato corporal de modo a sensibilizá-lo, capacitando o aluno a detectar suas tensôes e proceder à regulagem das mesmas (...)" (IMBASSAÍ, 2003, p. 53).

Essa tomada de consciência se mostrou importante também para a reflexão sobre a execução dos movimentos propostos na pesquisa de campo e as sensaçóes despertadas. Assim, os participantes foram estimulados a comparar a maneira de realizar determinados movimentos, com e sem a aplicação de algum princípio, conceito ou ponto de atenção do método Gyrokinesis. Observou-se que a aplicabilidade desses conteúdos despertou diferentes sensaçóes, tais como leveza, amplitude de movimento, equilíbrio, estabilização, menos tensão, alívio de dores, entre outros.

É válido destacar que essas sensaçóes não ocorreram somente nos encontros destinados à vivência do método Gyrokinesis, mas também na execução das sequências de dança clássica, proposta na segunda etapa da pesquisa de campo. Por exemplo, após a realização da sequência grand battment na barra, a qual consiste, no indivíduo posicionado 
em pé, elevar a perna à frente, ao lado e atrás, os participantes foram estimulados a refletir sobre suas percepçôes durante o movimento. Para ilustrar essa passagem, trago o depoimento da participante Raymonda:

(...) hoje eu senti minha coluna alongada e a perna leve. (...) Eu sempre tive dificuldade de perceber meu corpo colocado pra executar os movimentos. Eu sinto que geralmente eu faço muito movimento indevido com a pelve na hora de lançar as pernas, mas hoje sinto um equilíbrio, uma estabilização e com isso a perna ficou mais leve (Raymonda, depoimento concedido em 23 de fevereiro de 2016).

Nesse depoimento, a participante revela a ampliação de sua percepçáo corporal ao compreender como o próprio corpo deve estar posicionado para a realizaçáo de algum movimento. No caso específico, a mudança de postura proporcionou equilíbrio, estabilização e leveza nas suas pernas, conduzindo-a para a autocorreção, e consequentemente, para a superação da dificuldade salientada. Além disso, essa percepção contribuiu para o aprimoramento técnico da dança clássica, uma vez que, sendo o grand battment um movimento que requer estabilidade da perna de apoio, controle na coluna, quadril nivelado para manter as pernas livres sem tensão, a experiência realizada no encontro e as comparaçóes efetivadas pela participante estáo em concordância com o que afirma Fortin (1999), de que o trabalho com educação somática proporciona refinamento técnico de bailarinos.

Tais observaçóes demonstram que o principal resultado do uso da estratégia da educação somática denominada de comparação de partes e de sensaçôes do corpo, seja ela aplicada numa aula de um método somático ou de dança clássica, foram as suas contribuiçôes para o despertar das sensaçóes e o conhecimento do próprio corpo, como também nos processos de ensino e aprendizagem dos movimentos em dança clássica realizados na pesquisa de campo. 
A quarta estratégia utilizada foi o uso de imagens mentais, com o objetivo de contribuir para o processo de ensino e aprendizagem dos movimentos, bem como o despertar de sensaçóes. Assim, tomando a afirmação de Damásio (2011, p. 206), segundo a qual “(...) o cérebro precisa formar imagens, muitas imagens, no mínimo dos tipos visual, cinestésica e tátil; do contrário, a pessoa não pode executar os movimentos corretamente. (...)”, pode-se dizer que o uso de imagens mentais é uma importante estratégia de ensino e aprendizagem de movimentos, fundamental para o aprimoramento da percepção corporal.

Dentre as diversas imagens utilizadas, uma frequentemente evidenciada, tanto nos registros de diário quanto nos depoimentos dos participantes, foi a do "sorriso da clavícula”. Para explicá-la, julgo necessário esclarecer, primeiramente, onde essa estrutura óssea está localizada. A clavícula é um osso longo e curvado que articula medialmente ao esterno e lateralmente à escápula. Além disso, está situado horizontalmente logo acima da primeira costela. As duas clavículas formam uma linha transversal e podem ser facilmente observadas através da pele.

Haas (2011) afirma que os professores e instrutores de dança baseiam-se nessa regiáo para solicitar a ação de "abrir o peito". Porém, o uso dessa expressão, ou de "ficar reto", tem como resposta imediata "(...) os ombros para trás, peito estufado para frente, contração das escápulas (...) contração da lombar numa curva lordosante, hiperextensão dos joelhos com consequente rotação interna deles, pés em grande rotação externa, e finalmente, a cabeça compensa toda essa imposição, projetando-se para a frente" (MARETZKI, 2010, p. 104).

A imagem do "sorriso da clavícula" remete a uma sutil açáo iniciada do centro, na altura do esterno, para as extremidades, ao longo de toda a clavícula, permitindo que o participante posicione os braços de tal maneira que os ombros não fiquem tensos e nem sejam projetados para frente, tal como observa a participante Giselle, ao afirmar: 
Quando a professora falou do sorriso da clavícula, consegui sentir mais o movimento da coluna, e como consequência, o trabalho do abdômen. Isso se deu principalmente por ter percebido que ao realizar os movimentos que exigiam essa curva da coluna, eu, automaticamente, levava os meus ombros também. Porém, ao pensar no "sorriso", foquei minha atenção no que eu realmente deveria trabalhar. Isso fez muita diferença para mim. O ocorrido acima me fez compreender, sobretudo, como tudo é conectado e que às vezes pensar em algo que não faz parte do movimento desejado, ou seja, pensar em controlar outras partes acaba fazendo com que façamos o correto (Giselle, diário de campo, registrado em 18 de fevereiro de 2016).

O depoimento acima refere-se à realização do movimento de flexão da coluna em que, a partir da imagem do sorriso da clavícula, a participante compreendeu melhor o movimento a ponto de se corrigir. Verifica-se, então, que a imagem do "sorriso da clavícula" foi essencial para o alinhamento postural e a compreensáo dos movimentos propostos, tanto nas vivências do método Gyrokinesis como nos movimentos realizados nas aulas de dança clássica, pois proporcionou a autocorreção do movimento, uma vez que alterou o padráo automatizado do movimento.

E por fim, a quinta estratégia foi a denominada repetição do movimento, cujo objetivo era não somente a memorização dos movimentos, mas, principalmente, estimular que os participantes pudessem se observar e perceber o próprio corpo e ter a sensação mais clara do movimento em cada repetição. Nos encontros referentes à vivência do método Gyrokinesis as repetiçóes se alteravam, uma vez que a cada movimentação era acrescentado algum conteúdo, tais como os princípios, os pontos de atenção ou os conceitos complementares do método Gyrokinesis, contribuindo para a potencialização do movimento. Por exemplo, na execução da série de extensão acrescentadas movimentaçôes com os braços, variaçóes no 
ritmo respiratório, o direcionamento do olhar, a criação de espaço articular, entre outros. A cada conteúdo acrescentado, a cada ritmo respiratório alterado, se intensificava a movimentação da coluna, criando assim novas perspectivas sobre o movimento.

Toda vez que eu faço um exercício é de uma forma diferente. Como todos os professores sempre falaram pra gente, quando a gente vai repetir pra fazer de um jeito diferente, de sentir de um jeito diferente, mas aquilo só ficava ali na cabeça, vagava aquela informação. Mas agora, eu de fato faço de uma forma diferente porque aprendi a perceber o meu próprio corpo (Giselle, depoimento concedido em 18 de março de 2016).

Segundo esse depoimento, a repetição leva à transformação e ao conhecimento do próprio corpo, e não a uma simples reprodução mecânica de um movimento sugerido. Nesse aspecto, a estratégia da repetição empregada na pesquisa de campo náo foi compreendida no sentido de realizar o mesmo ou o movimento semelhante, mas no sentido de único e singular. Isso corrobora com Hanna (1986), quando afirma que a questão central na educação somática ocorre ao longo de um processo em que o indivíduo aprende a se conhecer a partir da percepção de si, ou seja, na perspectiva de primeira pessoa. Isto também é bastante compreensível a partir de MerleauPonty (2015), em que “(...) quer se trate do corpo do outro ou de meu próprio corpo, não tenho outro meio de conhecer o corpo humano senão vivê-lo (...)" (p. 269). Portanto, é essa repetição da diferença que permite o se conhecer, se perceber, despertar sensaçóes e consequentemente, alterar os padrōes automatizados.

Nesse sentido, foi necessário, durante a pesquisa de campo, estimular um repetir do movimento na diferença, buscando promover uma mudança integrada a partir das sensaçôes despertadas de cada participante. Daí a necessidade de se sensibilizar e se perceber, ou seja, escutar o próprio corpo

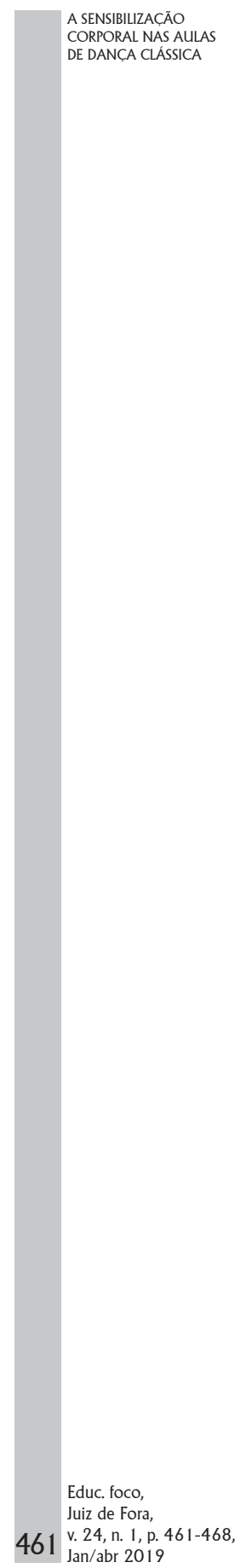


e realizar as ativaçóes necessárias. Um depoimento que ilustra essa observação é o da participante Sylvia:

Nos exercícios da barra (...) eu lembrava de alguma ativação que foi feita nos encontros (...). Em outros, eu senti que o meu corpo, tipo gritava, quando estava com alguma dificuldade. Ele gritava pedindo uma ativação de determinada musculatura pra facilitar o movimento. Então eu lembrava de alguma ativação (...). Eu senti muito, na hora dos pliés, a ação dos ísquios facilitando o movimento, na descida, na subida. Ficava parecido com uma mola. Leve, bem suave. $\mathrm{O}$ olhar facilitava muito a questão de abrir o sorriso da clavícula. Porque eu tenho muita dificuldade no ballet a postura, mas quando se leva o olhar, (...) fica mais dançante, fica mais suave, fica mais expressivo (...) (Sylvia, depoimento concedido em 23 de fevereiro de 2016).

Este relato revela as ativaçôes e os recrutamentos realizados pela participante nos movimentos de dança clássica, conforme as necessidades pessoais, para torná-los mais prazerosos, ou seja, uma mudança integrada a partir da sensação despertada pela repetição na diferença. Cada ação gerada é diferente e única, embora tenha nascido do mesmo esquema anterior, ou seja, de uma sequência de movimentos já determinada, seja pelo método Gyrokinesis, seja pela aula de dança clássica já estruturada. Para os participantes, a repetição é autoconhecimento e autocorreção, contribuindo assim para a percepção corporal e para modificar padróes de movimentos automatizados.

\section{CONSIDERAÇÓES FINAIS}

Souza (2012) afirma que na maioria das aulas de técnicas de dança o professor apresenta as sequências de movimentos, além de servir de modelo e determinar os resultados esperados. Isso se deve ao fato de que falar em técnica, sobretudo no território da dança, ainda pode ser interpretado como um treinamento físico exaustivo, repetitivo e ultrapassado, que 
causa lesóes aos praticantes (ROSÁRIO, 2013). No entanto, Vianna (2005) vislumbra que esta compreensão de técnica deve ser reatualizada e não mais compreendida como sinônimo de aquisição acumulativa de habilidades corporais, mas como um processo investigativo que proporciona caminhos para a construção de um corpo cênico.

Nesse sentido, o presente artigo refletiu sobre o processo de sensibilização nas aulas de dança clássica a partir da vivência do método Gyrokinesis, em que se fez uso de algumas estratégias da educação somática: o toque, a observação, a comparaçáo de partes do corpo e de sensaçóes, o uso de imagens e a repetição do movimento.

Tais estratégias, integradas ao processo de sensibilização, possibilitaram o despertar das sensaçóes, principalmente de relaxamento e de leveza, aliviando tensóes e dores, e preparando o corpo dos participantes para as atividades seguintes. Além disso, esse despertar contribuiu para que cada participante conhecesse o próprio corpo, o corpo do outro, bem como os limites e as potencialidades individuais, evidenciando, assim, a importância do conhecimento anatômico associado à sensibilização para o ensino de dança clássica.

Essa associação demonstrou ser importante também para facilitar a compreensão dos movimentos realizados ao longo da pesquisa de campo, contribuindo para evitar lesóes, tensóes e dores, e principalmente instigar cada participante a buscar seus próprios caminhos investigativos na execução dos movimentos. Esses caminhos foram traçados principalmente pela repetição dos movimentos na diferença, uma vez que se estimulou a observação de si, possibilitando que a cada repetição fosse elevada à enésima potência. Este procedimento foi importante, uma vez que contribuiu para a autocorreção, o aprimoramento técnico, e por fim, para a percepção corporal.

Comoresultadodeum estudoaindaem desenvolvimento, observa-se algumas lacunas, principalmente no que diz respeito à estrutura de uma aula de dança clássica sob o viés da educaçáo somática, bem como aos entrelaçamentos dos 
movimentos da dança clássica a partir de vivências em outros métodos somáticos.

Porém, por ora, este estudo evidenciou que o processo de sensibilização corporal numa aula de dança clássica parece ser um caminho possível para tornar o bailarino um investigador do próprio movimento, tal como salientado por Domenici (2010), como também contribuir para as transformaçôes no ensino da dança clássica, uma vez que ela é uma linguagem viva e que, segundo Vianna (2005), sempre haverá possibilidades para as contribuiçóes individuais.

\section{REFERÊNCIAS}

BOLSANELLO. D. Educaçáo Somática o corpo enquanto experiência. Motriz, Rio Claro, v.11 n.2, p. 99-106, 2005.

BOLSANELLO. D. Afinal, o que é educação somática? In: BOLSANELLO, D. Em pleno corpo (p. 18-31). Curitiba. Brasil: Juruá Editora, 2010.

DAMÁSIO, A. E o cérebro criou o Homem. Tradução Laura Teixeira Motta. São Paulo: Companhia das Letras, p. 439, 2011.

DOMENICI, E. O encontro entre dança e educação somática como uma interface de questionamento epistemológico sobre as teorias do corpo. Pro-Posiçóes, v. 21, n. 2, p. 69-85, 2010.

EDDY, M. A brief history of somatic practices and dance: historical development of the field of somatic education and its relationship to dance. Journal of Dance and Somatic Practices, 2009, v. 1, n. 1, p. 05-27.

FRANKLIN, E. Condicionamento físico para a dança. Barueri: Manole, 2012.

FORTIN, S. Educaçáo Somática: novo ingrediente da formação prática em dança. Cadernos do GIPECIT. Grupo Interdisciplinar de Pesquisas e Extensão em 
Contemporaneidade. Imaginação e Teatralidade, Salvador, n. 2, p. 40-55, 1999.

HANNA, T. What is somatics? [Versão eletrônica] Somatics: Magazine-Journal of the Bodily Arts and Sciences, v. p. 4, 4-8, 1986. Disponível em: <http://somatics.org/library/htl-wis4. html >. Acesso em 15 out. de 2014.

HASS, J. G. (2011). Anatomia da dança. Traduçáo Paulo Laino Cândido. Barueri, SP: Manole.

HOMANS, J. Os anjos de Apolo: uma história do ballet. Lisboa: Edições 70, LDA. 2012.

IMBASSAÍ, M.H. Conscientização corporal: sensibilidade e consciência no mundo. In: CALAZANS, J.; CASTILHO, J.; GOMES, S. (eds.), Dança e educação em movimento. (pp. 47-57). Sáo Paulo: Cortez, 2003.

LAWSON, J. Ballet Class: principles and practice. New York: A\&C Blacks Theatre Arts Book. 1988.

MARETZKI, G. Corpo Análise: soma e psyché construindo uma relação equilibrada. Rio de Janeiro: Senac Nacional, 2010 .

MERLEAU-PONTY, M. Fenomenologia da Percepçáo. São Paulo: Martins Fontes, 2015.

ROSÁRIO, R.L. Conexóes em movimento: o ensino da técnica do Ballet a partir dos princípios do método Gyrokinesis ${ }^{\oplus}$, 2013. 131f. Dissertaçáo de mestrado em Artes, Universidade Federal do Pará. Belém, Brasil.

ROSÁRIO, R. L. Os métodos da educação somática nas aulas de dança clássica. Alicerces Revista de Investigaçáo, Ciência e Tecnologia, n. 6, p. 215-226, 2016. 
SILVA, M. L. P. (2015). As peles que dançam: pistas somáticas para outra anatomia. 2015. 112f. Dissertação de mestrado em Artes, Universidade Federal do Ceará. Fortaleza, Brasil.

SOUZA, B. Corpo em dança: o papel dos métodos somáticos na formaçáo do dançarino contemporâneo. 2012. $115 \mathrm{f}$. Mestrado acadêmico em Dança. Universidade Federal da Bahia, Bahia, Brasil.

STRAZZACAPPA, M. A formação do professor de dança. In: GONÇALVES, Thaís; BRIONES, H.; PARRA, D.; VIEIRA, C. (org). Docência-artista do artista-docente. Seminário Dança Teatro Educação. Fortaleza: Expressão Gráfica e Editora, 2012.

VIANNA, K.. A dança. 2a ed. São Paulo, SP. Brasil: Siciliano, 2005.

\section{Depoimentos Escritos}

Giselle (2016). Diário de Bordo. [Depoimento registrado em 18 de fevereiro, 2016 e concedido à Rosana Rosário].

\section{Depoimentos Orais}

Cinderela (2016). Entrevista. [Depoimento registrado em 07 de janeiro, 2016 e concedido à Rosana Rosário].

Corsário (2016). Entrevista. [Depoimento registrado em 07 de janeiro, 2016 e concedido à Rosana Rosário].

Giselle (2016). Entrevista. [Depoimento registrado em 18 de março, 2016 e concedido à Rosana Rosário].

La Bayadère (2016). Entrevista. [Depoimento registrado em 14 de janeiro, 2016 e concedido à Rosana Rosário].

. Entrevista. [Depoimento registrado em 11 de fevereiro, 2016 e concedido à Rosana Rosário]. 
La Sylphide (2016). Entrevista. [Depoimento registrado em 12de janeiro, 2016 e concedido à Rosana Rosário].

Raymonda (2016). Entrevista. [Depoimento registrado em 23 de fevereiro, 2016 e concedido à Rosana Rosário].

Sylvia (2016). Entrevista. [Depoimento registrado em 23 de fevereiro, 2016 e concedido à Rosana Rosário].

\section{Agradecimentos}

À CAPES, pela concessão de bolsa de doutoramento nos anos de 2015 a 2018, a qual viabilizou o desenvolvimento desta investigação.

Às professoras doutoras Maria José Fazenda e Vanda Nascimento, e ao professor doutor Jorge Ramos do Ó, pela orientação e apoio na investigação em desenvolvimento.

Aos participantes deste estudo, os alunos do Curso Técnico de Dança Clássica da Universidade Federal do Pará, os quais se disponibilizaram em fazer parte da pesquisa de campo. 
